\title{
Introduction
}

The first edition of this book has been a best-seller and a decade later Edinburgh University Press invited the editors to work on a second, enlarged version. This has involved including extra sections and expanding others with reference to new issues and developments during the last ten years. Two new authors have joined four of the original team to complete the book and we are confident that this second edition will be as useful and relevant as the first.

Both editions have grown out of the conviction that crossing the frontiers of faiths, languages and races can enable people to deepen their understanding of issues that are important to us all. We live in an age when many different groups, particularly in Europe and North America, are expressing serious concern about human values - about how we should live, how we should treat each other and how we should treat our world. This concern is one for all citizens, but is being articulated particularly by politicians, members of the caring professions, in education and in discussions between members of different faiths. Often the most rigorous and challenging answers come from people of faith rooted in religious traditions. They challenge each other with their different language worlds and starting points, but also startle us with answers that express values which are often shared. The central aim of this book is to make available the basic tenets of six so-called 'world' religions, six major religious traditions - their beliefs, experiences and convictions - in which these shared values are grounded. We acknowledge that many other religious traditions and secular world views than the ones we have included have important contributions to make to this debate and their omission is not one of principle but of space. Bahais, followers of Confucius, Daoists, Jains, those who practise a Shinto path and Zoroastrians, for example, also have important positions on the issues under discussion. We also acknowledge that it is the people of faith rather than the 'isms' of the systems that negotiate the traditions and make the choices, and that these are almost infinitely varied. This variety is found within traditions as well as between them (see section 1).

Any context has its strengths and weaknesses. It is sometimes suggested that the treatment of values and ethical issues in the Western world, even when faiths come together, is dominated by a Christian or post-Christian agenda, and that this is a weakness. From this standpoint any list of common topics such as those to be addressed in this book may be seen to reflect the concerns of the majority culture, which may be secular or religious, rather than minority faiths; the concerns of the West and not of other parts of the 
world. Examples of this bias of concerns can be seen in any distinctions made between public and private lives and the inclusion of any focus on gender and issues such as surrogacy, homosexuality or euthanasia. It might well be suggested that each faith should set out its own themes and group them in its own way. This is a viewpoint with which the contributors are sympathetic and comments have been included on the appropriateness of terms that are used and whether or not those within a tradition have anything to say on the topic so labelled. It would not, however, have produced a text which would be as useful when considering the question of shared values in the European and North American as well as other contexts. The text therefore does arise in a Western context, and the contributors, some of whom are members of the faiths about which they have written, accept that this is the case. It is also a major strength of the book that this has been done. For it is precisely the tensions between context and the world views of the various faiths which force reflection on assumptions and convictions which within that context are generally taken for granted - for instance, the private-public classification.

The topics were chosen for a variety of reasons. They provide an opportunity to focus on issues that are important within religions, even though in different ways or to a different degree. They are also being raised in professional groups and have been placed in some way or other on syllabuses in educational institutions. However, the editors have always kept an eye on any artificial moulding of material or traditions. As indicated above, writers were asked to point out where any terminology or emphasis is not that used within a particular faith, or where there is as yet little material or debate on a particular topic, for whatever reason. For example, the section on Buddhism has used the heading 'Human Nature' (see B.6.b) instead of 'Sin and Sins', which would not be appropriate terminology for Buddhists in this context. At the same point (see D.6.b), the Jewish author writes that 'the overarching concept of Sin is not really present in Judaism'. In the Sikh section on euthanasia (see C.5.e), it states that 'this is not a subject on which Sikhs have made any religious pronouncement'. What is apparent, though, is that questions on the agenda in a Western context are drawing more and more response from the traditions whose roots have been until quite recently in quite different societies. Addressing these questions is part of the transplantation process of religious communities and not an artificial task. The diaspora communities are now making a significant contribution to public debate. Each section has an introduction in which the concerns and emphases of each faith are explained in their own terms and in their own way. These passages 'set the scene', and hence prevent the common structure from moulding the material in an artificial way. There are also differences in the length as well as the contents of sections and this gives each faith an additional opportunity to show the balance and emphasis of concern for members of the traditions within it. The editors are very aware that there have been attempts, such as that linked with the 1993 centenary celebrations of the 1893 Chicago Parliament of Religions 
(see Küng and Kuschel 1993), to try to identify a 'global ethic' to which all religions might agree and with a statement that many groups signed. This is an interesting enterprise but of another kind from the task undertaken in this book, where the contributors are attentive to differences even though working within agreed areas of concern.

All of the writers have academic expertise in their given faiths and are sensitive to the kind of debates outlined above. They are also either members of the faith communities or have worked closely with those communities and are respected by them. They have tried at all times to reflect the viewpoints of believers and belongers, of those who are insiders to the traditions. In doing this they have used ancient scriptural and other more contemporary written sources, and tried at all times to reflect the variety of views that exist on the many controversial issues within the different traditions. These varieties are to do with different historical contexts and the new diasporas, the geographical and cultural arenas in which members of faiths increasingly find themselves. Many of the issues are on the frontiers of debate in the faiths and there may be no such thing as a fixed or final view. Interpreters and interpretations are many and have varied authority. It is often as important to understand how decisions are made and how guidelines are being laid down as to know what is being decided. Readers are encouraged to seek further views through meeting members of faith communities and through further reading, including looking at journal and newspaper articles and web sites. The lists of addresses and bibliographies at the end of each section and the book as a whole facilitate this further exploration.

As has already been mentioned, there are other important religions and communities that are not discussed here for reasons of space, rather than from any suggestion that they are not important. The viewpoints of these communities add further diversity and emphases to debates on ethical issues. As a result of the stimulus that this book gives, readers are encouraged to find out, for example, about Jain attitudes to animals, Daoist approaches to the environment, Bahai attitudes to peace, Zoroastrian (Parsi) views on other religions and marriage, Confucian attitudes to social responsibility or Rastafarian attitudes to drugs and poverty, the attitudes of members of indigenous religions such as the first nation peoples of North America to issues of identity and authority, the attitudes of any of the new religious movements derived from older tradition towards women, or humanist attitudes to euthanasia, to name but a few possibilities. Priorities and populations vary, even in the so-called 'Western' world. In the USA responses to the issues by the African-American populations are crucial and would add yet further perspectives to the material. Also not discussed may be some aspects of political behaviours which are claimed to be manifestations of a religious tradition. We have allowed our contributors to determine what is beyond the pale and fully endorse the view that not everything done in the name of a religion is a true representation of that tradition. 
The section on each religion is presented separately as a free-standing and integral piece of writing. This is another way of trying to see each tradition in the round and in its own terms. If the themes had been dealt with across each religion and one at a time that would have given the reader much less sense of how aspects of a religion's viewpoint are part of a whole. As the text stands, cross-reference where needed is indicated and also facilitated by the index and the common structure used for each faith. Each religion begins with an introduction to what it means to be a member of that religion, with its own authorities, norms, ideals and interpreters. There is no particular significance in the order of the religions being presented, but it seemed sensible to group together those which began in India and are often referred to as the 'Indian' traditions, the Hindu, Buddhist and Sikh faiths, though the modern state of India includes many others that both began and have been transplanted there. The other group is the so-called Abrahamic faiths which are the Jewish, Christian and Islamic traditions.

\section{USING THE BOOK}

This book is intended for a wide audience. Experience from the first edition suggests that it will both inform and support discussion in many arenas. It can be read through section by section as a thematic introduction to a tradition. It can also be used to explore an issue across any two or more faiths by using the headings or the index or preferably both. Ethical issues are an area of increasing interest. This is obvious from media attention, the increase in publications covering ethical issues and the popularity of courses in ethics in schools and universities. The growth of interest runs parallel to the many practical and ever more complex day-to-day challenges and decisions that have to be made in people's lives, sometimes at high speed.

This book, therefore, might be used for reference by those in the media, as a basis for training sessions by the caring professions, as substantial research material by teachers and students or as a stimulus for reflection by interfaith groups or indeed by individual faiths for whom such material is sometimes hard to find in a single source. There are various ways in which a reader might proceed to do any of the following:

1. Read a section on an individual religion as a rounded introduction to a world view within which ethical decisions are made. This material complements in a rooted contemporary way material found in other introductions to these religious traditions.

2. If more is wanted, lists of references at the end of each section can be used to extend work on a particular tradition or a theme within that tradition. For example, there are whole books on women in Buddhism, marriage and divorce law in Islam or Jewish approaches to medical ethics. 
3. Since the reader is also encouraged to think in terms of people of faith and their decision-making process, not just systems, the address lists on individual religions support the possibility of meeting people and exploring a tradition through personal contact. There are also contact details to organisations such as The Interfaith Network UK which can put you in touch with communities and organisations.

4. The above process is also relevant for exploring more than one religion.

5. If the reader's main interest is a specific issue, then both the thematic listings and the index can facilitate access to approaches very specifically for comparison and as a stimulus to debate and the development of further questions. For this reason each issue is identically numbered in each section. This has the disadvantage of appearing to force a common tenplate of priorities and values on each tradition, but the editors feel that the disadvantage of this is outweighed by the advantage of facilitating comparison across traditions.

So to summarise, the reader has explanatory text in the main part of the book relating to six religious traditions and with reference to a wide range of issues. There are also suggestions for further reading at the end of each section and at the end of the full text. Important, too, is the support given for making contacts with members of different faiths, in both the lists of addresses given at the end of each section which are religion specific and more generally at the end of the book. Each section also has a glossary of terms.

\section{THE THEMES}

\section{Religious Identity and Authority}

Being a member of one religion or world view rather than another is often a matter of people's country of birth, their general cultural background or the particular family from which they come. In this case the attitudes of that religion are absorbed gradually, becoming both as much a part of people's lives as the language they speak - something with which they feel 'at home' and towards which they have considerable loyalty and affection. Nevertheless, there are people who find that at some stage in life they want to change from the religion they grew up in to another religion or world view which they feel is a better expression of what they really think or how they want to live. In addition, there are more and more people who grow up with no religious background at all, in what are usually called 'secular' societies. These people may never want to commit themselves to a religious view of the world or may become attracted to a religion and embrace it, often through meeting people whose ideas or way of life impress them in some way.

Many members of religions emphasise that it is not enough simply to believe certain ideas: a religion is a whole way of life. This is obviously a very 
important perspective for a book on ethics and so inevitably it is one which the authors have taken into account. Of course, not all members of a religion can or do follow the ideal path of life that the religion teaches, and hence many sections in this book contain examples of the gaps between theory and practice, or ideal practice and reality. Every reader will be able to bring to mind examples where the dominant voice of a tradition may teach a certain ideal but where individuals within that tradition have felt guided by their individual consciences or the pressures and possibilities of personal circumstances and do not feel able to live the ideal. Examples might be Roman Catholic Christians on abortion or some methods of contraception; Hindus on non-violence; Sikhs on the consumption of alcohol; Jews on interreligious marriage; Muslims on caring for elderly parents; or Buddhists on suicide. The authors also set out to give expression to the diversity that exists within all religions, a diversity which often has something to do with where the religion is being lived. There is now a great deal of research on the changes to religious lives brought about by diasporas transplanted from their traditional environments. For example, Hindus or Muslims in Britain may make different decisions on marriage or family life from those in India or Saudi Arabia, and their religion provides for that possibility; Buddhists in Tibet may make different decisions about eating meat from those in Switzerland; Sikhs in the Punjab may find their struggle for justice of a different kind from Sikhs in Canada; some Jews in the USA may have a very different attitude to international politics from Jews in Israel; Christians in Africa may have very different views on gay rights from those in North America. On top of this, all religions are made up of different groups, schools, denominations and sects and these often disagree strongly with one another, creating tension between members of different groups. There is also the feeling that belonging to a religion is like being part of a worldwide family which transcends other barriers. As civil legislation in various countries and internationally enters more and more the territory which was traditionally reserved to religions - for example laws about marriage and divorce or gender equality - religious communities are being forced to respond.

One of the distinctive features of religions is the belief that this life and the world as we know it are not all there is. This does not detract from the importance of acting for the good of other people in the world, but it does mean that there is a further dimension to people's actions and the fruit those actions bear, a dimension unseen by other human beings. This makes teachings about karma and rebirth, heaven and hell, afterlife and the kingdom of God an important part of ethical discourse. There are this-worldly social orientations to teachings and also other-worldly factors to beliefs and actions. In some traditions these challenge each other.

The religions in this book all have substantial collections of written texts or scriptures on which they draw for help in making ethical decisions. All these texts have a certain authority, even though believers describe it in 
different ways. Some texts, for example, have the status of revelation or 'givenness', while others derive their authority from being collections of traditions or the reflections of distinguished teachers on important issues. These texts may be interpreted in different and even conflicting ways by different groups and individuals within traditions.

Nearly every community, both secular and religious, has leaders. It is often instructive to discover how these leaders are chosen and by what kinds of qualities they are judged. Throughout history too, communities have tried to establish whether leaders are above the law or within it. Particularly important for communities who live under leaders of a different religious or secular tradition is the question of the appropriate attitudes towards such leaders: what duties do subjects or citizens owe, and what are the qualities to be looked for if these leaders are elected?

In the context of religious communities, it is important to discover the relationship between religious leaders, the tradition and the community's original inspiration which is often in the form of texts. In addition to texts, there are many people whom members of religions consider to be great ethical examples. These might be great figures at the origins of the religions, such as Moses, Sarah, Muhammad and Khadijah. They might be later historical figures such as Ashoka or Guru Gobind Singh. They might be wellknown figures from the twentieth century, such as the Dalai Lama, Aung San Suu Kyi, Dietrich Bonhoeffer or Mother Teresa of Calcutta, or they might be people who live without any fame or publicity but whose lives of quiet love, self-sacrifice, bravery, honesty and loyalty to their faith greatly influence their families and friends. You may know such extraordinary ordinary people in your own neighbourhood, and they are often women.

\section{Personal and Private?}

The title of this section needs a question mark because the distinction that is often made in the Western world between people's public and private lives is not one sustained in many cultures and religious traditions. This is pointed out very clearly in the sections on Hinduism, Sikhism and Islam particularly. People are seen in these cultures as essentially parts of a family, probably an extended family unit and a wider community. What they are and do is a part of the community's life, honour or blame. They do not make their decisions on such an individualistic basis as do many people in the secular West.

Nevertheless, religions offer guidance on the kind of qualities (see 2.a) that should be admired or cultivated by individuals, even though they go about making their decisions in two broadly different ways. Some traditions lay down fairly clear guidelines and advice. They offer models, particularly early figures or founders, as prime examples of the kinds of qualities to be encouraged. Other traditions provide a looser kind of guidance, with inspirational 
ideas, parables and messages from which individuals can draw their own conclusions as to how the ideal life should be led.

Most of the religious traditions seem to agree that humility is a necessary quality, as are honesty, kindness and wisdom. Wisdom here is not the same as cleverness or even education; honesty is not the same as bluntness; kindness is not the same as sentimentality and is a less misleading term than love. One of the reasons for cultivating the personal qualities described in this section is so that the relationships one establishes with others are not only enriching but also inspiring. The way an individual relates to friends is perhaps the easiest test of the kind of moral life that she or he conducts.

For some religions, though, friendship is only a halfway house to the love of humanity as a whole, which is implied in the concept of the human race as one family. In others it is the highest form of human relationship, the one which sets goals and challenges and also provides a model of the kind of relationship that could be achieved either with God or with all humankind.

Best friends and early friends are often very important in people's lives. Every community has proverbs and sayings about the need to choose or have good friends and about the danger of having bad ones. In some, though by no means all, people's assessment of ethics and moral principles, relationships with friends need even more discussion than those with family members since people have the right to choose their friends. Therefore it is not only important how people behave towards a friend, but also how they go about gaining one in the first place, not to mention maintaining the friendship once it has been achieved. In most cases religions talk about friendships between people of the same sex. Nevertheless, this provides an intimation of the ideals in heterosexual relationships before marriage (see 2.c) and which should continue within marriage (see section 3). This is especially important since for some, the most fulfilling friendship they will ever have is with their partner in life. Throughout history people have tried to anticipate or experiment with the preliminaries of this relationship through sex before or outside marriage. Since many religions place great stress on marriage, this is an area in which religious traditions may want to present strong views.

What is also stressed is the importance of the family. While the pattern of the family and one's responsibilities to it may differ from religious community to religious community, and sometimes, depending on cultural contexts and individual interpretations, even within the religions, it would still seem to be true that the responsibility of bringing forth new life is regarded as a serious one. Before the advent of what is seen as 'safe' sex for people in some parts of the world, there seems to have been particular concern about the consequences to the woman, either in terms of her reputation, her economic security or her emotional stability of bearing a child without a man to support her in its upbringing. It is technically possible now in most parts of the world for a woman to ensure that she does not have a child through sexual intercourse. It is also more possible in these same contexts for a woman to bring up a child 
on her own. Nevertheless, it would still appear that most religious communities consider that to have a sexual relationship without ever having any interest in having children and of both partners accepting intercourse if you are fertile without at least the general possibility of conceiving a child during the duration of the relationship is almost a contradiction in terms, since part of the function of having sexual intercourse is to do with having children.

Many religions seem to agree that the physical act of sexual intercourse in the appropriate loving context is a 'high' act rather than a 'low' one. It is usually linked with the procreation of children or the expression of a pure lifetime's love between two individuals. It would also appear that there is an attitude emerging on the part of the liberal wing of several communities that, while sex before marriage is still technically unacceptable, if it is performed by two individuals who intend to marry, it is less unacceptable than if performed by two individuals who have no intention of any particular mutual commitment.

For some religions, marriage is the norm and celibacy discouraged. But some communities teach that it is better not to be involved in the sexual act in any context and that sexual desire needs to be sublimated or ennobled. Celibacy is then an important ideal and may be seen as the highest way. These different views co-exist side by side within some religious traditions as well as between traditions.

Still more problematic for most religious traditions has been sexual activity with a member of the same sex. Deep relationships with people of the same sex are often set up as the highest form of friendship but many traditions seem to have deep taboos against homosexual, gay and lesbian activity. Recently it has been stressed that even those traditions that feel most strongly about the subject do not condemn the homosexual, but the actual sexual activity. While that may seem to some like a very subtle line to draw in real life, it does at least make clear that the kind of abuse, ridicule and even physical attack that many homosexual men, for example, may experience in some societies cannot be justified by appeal to any of the religious traditions represented in this book. In some religious traditions the ethical stance is by no means clear cut (see B.2.d and E.2.d) and there is considerable debate which invokes strong argument and feelings.

As has already been indicated, not all religious traditions have articulated clear positions on all issues included in this text. In respect of HIV/AIDS, some groups do not want to acknowledge the growing problem (see, for example, C.2.e), others see chastity as the only way forward (see, for example, A.2.e) and others emphasise the overriding approach of compassion towards sufferers without more explicit ethical comment.

\section{Marriage and the Family}

Marriage is one of the four rites of passage or stages of life marked by some religions, albeit in different ways and with different emphases. The other three 
rites usually listed are at birth, puberty and death, though Hindus have a longer list of samskaras (see A.3.a) and Buddhists do not consider all these stages as religiously significant in the same way (see B.3.a). Hindus also have another list of stages of life for the twice born. Some religions think of marriage as a path to follow for those who cannot be celibate and cannot devote all their lives to religious matters in an ascetic way. In these religions, married life is usually acknowledged as a lower path than that of a monk, nun or world-renouncer. Other religions view marriage as the norm, and getting married as a fulfilment of the religious life.

Whether it is seen as the recommended way or a lower path, and whether there is a religious ceremony or not, all religions take marriage very seriously because it forms the most basic unit in society into which children are born and nurtured in the faith. Most faiths emphasise that it has much wider implications than the attraction, personal happiness and fulfilment of one man and one woman. This is expressed in various ways: for example, in accepting or approving a system of arranged or assisted marriages where the extended family is involved in the process of choice and commitment and the support of a couple. Marriage can be seen as one of the sacraments of a religion, accompanied by special religious ceremonies in a place of worship and/or in the presence of a priest (see, for example, A.3.a and E.3.a). Alternatively there may be emphasis on a publicly celebrated social contract with witnesses (see, for example, F.3.a).

Some marriage ceremonies have similar features wherever a religion is transplanted, but some are entirely dependent on the social customs, as well as the legal requirements, of a particular country. Not all religions insist on monogamy, although they say that believers must observe the law of the country in which they live. They all have a strong sense of an appropriate and ideal relationship between a wife and husband, of the importance of having children and of mutual help in their different roles.

A marriage begins or extends a family unit, and family bonds are some of the most important in people's lives. The relationships between parents and children are emphasised particularly in religions because the child's early spiritual as well as physical and emotional life is nurtured within the context of a family. But many religions embrace an obligation to respect and care for not only the closest family members but the extended family of grandparents, aunts and cousins as well. This may have something to do with the traditional societies in which most of the religions began, but it may also express a deep understanding of the network that is needed to sustain the life of an individual.

The principles of respect, obligation and love emphasised in marriage are also frequently extended to the wider family of the religion. All these relationships are seen as an enrichment as well as a responsibility. They give security and help at crucial stages in people's lives, as well as mutual obligations. The personal qualities that are needed for family relationships are 
also those which the religions encourage in the wider world (see section 2.a). It is important also to ask whether there are ever situations when the demands of a religion might challenge and override the commitments people have to their families and how these are resolved, as for example if someone becomes a Buddhist or Christian monk or nun. However, family permission is required for a person to enter the Buddhist monastic sangha even if the person is technically 'of age'. There are now also many people who live single lives and their place in the community needs to be considered. Religions may have very different approaches to these questions in different circumstances.

When people enter into marriage, all religions have a strong sense of the importance of marriages that last a lifetime and ensure a stable home life for the whole family unit. This is the ideal set before those about to be married, and to which members of the religion give their support. If a couple are encountering difficulties the extended family and the wider religious community will usually do all they can to help them, and to encourage them to stay together. There may be a stronger sense of the rightness of staying within a marriage than in Western societies at large which may accept more easily divorce as the lesser of two evils if a marriage is unhappy. People now often debate what is meant by a family and whether the unit in which one lives, whatever the mixture of human beings, counts as a family group. Members of religions may be sympathetic to this idea of what is meant by a family, emphasising that loving and supportive relationships are the touchstones of family communities, or they may be very critical of new ways of living together. There may also be considerable tensions between religious ideals and the custom of the land in which a member of a religious community lives, between the traditional sense of being a part of a community and modern individualism.

When traditional marriage relationships do break down, there is often both compassion and realism in what is allowed by many religious groups, and in the last resort, practical arrangements can almost always be made for a divorce to take place. The reasons why a divorce may be permitted, if at all and the difficulties involved in the process, will vary from religion to religion, and the nature of divorce will depend on whether the original marriage was a purely legal contract or a sacramental act. Like the original marriage, it should be acceptable to the laws of the country in which the couple are resident.

\section{Influences on and the Use of Time, Money and Other Personal Resources}

Education in the broadest sense is without doubt the main medium by which any culture or tradition transmits its values to others, particularly the next generation. There is a clear difference of opinion as to whether education in a faith should be given intensively to the leaders so that they can lead others 
effectively, or whether it should be given on a more widespread basis so that everybody has a fair knowledge of what the values might be and what is expected of them. In the UK there is also a debate about faith-based schools in the general education system and whether these divide communities and potentially breed ignorance and subsequent prejudice against the 'other' or whether they allow potentially vulnerable religious communities to transmit their values coherently in the face of an otherwise pervasively secular culture.

Whatever the preferred solution, it seems generally agreed that education is not primarily about developing skills to fulfil jobs or to become an economically productive member of society but more about developing the correct attitudes and personal qualities to be a fine human being. This is an attitude shared by people with religious as well as secular ideals. In trying to work out what should be taught as well as to whom it should be taught, every culture finds itself defining its major values and teachings. In many cases these are based on central and important texts and the understanding of them. What is particularly instructive is the wide variety of methods of teaching and learning that the different cultures have arrived at over the centuries. Methods of education vary from learning by heart sacred texts and doctrines to discussion of why those in a tradition think and act as they do and whether modern contexts should effect change.

As well as the influence that families and education have on people's values there is also the influence of the media and the power of advertising in people's lives. The media can be used for good purposes or to manipulate the minds and attitudes of people. Propaganda has always been used in societies, including by religious groups. Religious communities as well as media moguls can be accused of manipulation and indoctrination in respect of the needs of the young. Mass printing and publishing and the electronic media mean that more people can be influenced more quickly and therefore more potential harm can be done. Advertising presents another aspect of the potential misuse of these resources. Obviously a manufacturer or seller has the right to inform people of the goods or services available. However, with the increased power of the media and a growing understanding of how the human mind works, modern advertising can manipulate so that it is not offering the buyer an opportunity, but rather implanting an instruction to purchase the item in question. This clearly presents major moral and ethical challenges, and many societies have attempted to work out codes of practice.

In addition to radio, television, magazine, newspaper and telephone advertising there is now the world wide web as a propaganda tool as well as a neutral information highway and genuine educational resource. Various ways of regulating that by national and international laws are now frequently under discussion. While the traditional teachings of the religions discussed in this book were established long before advertising and the world wide web were a 
major issue, there seem to be some guidelines that can be drawn from the ethical teachings embedded within them.

Although it has been said that education is primarily about wisdom rather than skills, each tradition nevertheless lays great stress on the importance of individuals playing a constructive part in society. This does not necessarily mean that the work done by each person must be of economic value but it does mean that everybody must contribute in some way or other to the success and improvement of the world in which they live. Besides the production of goods and services, people might be expected to work as teachers, religious professionals or even thinkers for the betterment of society. All the religions discussed in this book have at some time or another felt it important to enable certain individuals to devote almost their undivided attention to thinking and to extending their own learning for the enrichment of the society in which they live. This is also considered to be work.

The performing of a useful task is seen not only as important to society, but also to the individual in so far as it increases self-respect and dignity in the eyes of others. Any tendency to judge a job's worth by the money it earns is more alien to these religions than to society at large, where it is an important indicator of value. Many of the most valued jobs and workers in and for the community do not earn anything at all but give their time and skills in an entirely voluntary way. Also Buddhist monks and nuns, for example, live entirely on the offerings of members of the lay community and are valued for their contribution to that community.

In Judaism the concept of leisure is enshrined as an absolute value through the concept of Shabbat. Any idea of leisure as self-indulgence seems alien to the religions and there is a greater sense that the time when an individual is not involved in his or her job might be spent not only on self-enrichment but also on social interaction and the enrichment of others.

The balance between these two sides of the coin - work and leisure - is seen differently by the different religious traditions. It is an important issue for modern technologically developed societies which are struggling with the apparent lack of jobs in relation to the number of people who wish to have them. It seems to be the message of all the traditions that every individual should have the opportunity to work. It is interesting that in relation to the Buddhist monastic tradition's way of life, meditation is called 'the work of the monks and nuns' and there is a similar attitude to the Christian attitude of contemplative prayer as 'opus Dei'. On the other hand, the leisure that people have is that time which is in contrast to the work that they do. The balance seems to be important. At the moment employment and unemployment trends in Western countries seem to have produced a situation where some people are overworked all the time and some people have enforced inactivity and the indignity of unemployment.

There may be some people who have excess leisure as a product of their wealth. The religions disagree as to whether or not individuals are to be 
allowed to accumulate wealth. The debate has a remarkably contemporary ring to it. Some suggest that since wealth can corrupt and provoke the evils of greed and selfishness, everyone should be allowed to have approximately the same amount and that the collective wealth should be shared for the good of society. Others argue that if individuals with the right kind of initiative are allowed to accumulate wealth, their affluence, if properly controlled and guided, can serve to benefit those less well-off than themselves and enhance the quality of a community's life with charitable activities.

One thing seems clear as far as these religions are concerned. Wealth is always given in trust to the individual and must be used responsibly and morally. The wealthy individual automatically has a responsibility to those who are poor, making the (compulsory) paying of taxes or the (voluntary) contribution to charity an absolute responsibility rather than an act of goodwill. Even those religions which agree that individuals have every right to accumulate wealth are nevertheless quite clear that there are correct and incorrect ways of accumulating it. Some money, however good the cause to which it is given, will be 'dirty' because of the way in which it has been earned.

One way in which some of the richest people in the world have achieved their wealth is through drug trafficking. This is widely seen as a way of life that exploits other people since it encourages and then trades on people's addiction. While there seems to be a case to be made by some of the traditions for the use of certain drugs or alcohol to heighten spiritual or mystical awareness and certainly to ease pain in the case of illness, when it involves the abuse of an otherwise healthy body it is roundly condemned. Certainly when people slip into addiction which can lead eventually to sickness, death, loss of personal autonomy and their destruction as individuals with integrity, each of the religions speaks out strongly to condemn. What individuals do in this as in other examples affects whole communities.

It is a seeming paradox that drug abuse is a problem of the very rich and very poor. It would appear that people turn to drugs out of boredom or despair. In either case perhaps some of the approaches to work and leisure could help to resolve the drugs problem that the world appears to face.

\section{The Quality and Value of Life}

The major religious traditions of the world all teach that human life is of great value and should be respected whether the individual is elderly, handicapped, sick, poor, dying or, in some cases, not yet born. In some ways they go even further than this and say that the life experience of some of these people may bring them especially close to the heart of their religion, in a way that the experience of youth, physical fitness, intellectual ability and wealth do not. The religions also teach personal qualities (see 2.a) which give priority to the practical care of the poor and sick. These include a sense of justice, 
unselfishness, generosity, love and compassion. In the light of this a whole range of reproductive technologies in addition to abortion raise very deep questions with which religions are struggling to engage. These focus on the origins of life and the status and nature of human life in particular.

The attitudes of single religions, such as Christianity in the UK or Islam in Saudi Arabia or Buddhism in Thailand, have sometimes permeated whole societies and influenced their laws on financial assistance and health care for those in need, and their attitudes to abortion and euthanasia. In other societies such as Singapore the existence of a plurality of religions has underpinned what might be called a 'caring' attitude and a respect for life, even when there is disagreement about the exact moment the human person comes into being. But religious people are now in the minority in many dominantly secular societies where people may value material success and a busy, efficient life in paid employment rather than anything else. These attitudes are more and more the norm and make the elderly, handicapped and poor feel useless and social failures. This attitude also affects those who are home-based carers such as many parents, particularly mothers, and those who look after elderly relatives. There is also a high level of scientific experiment and technical achievement which enables people to have safe abortions for social reasons, and which present death as a medical failure instead of the natural and acceptable end to life. Religious people are affected by and interact with these attitudes in many different ways and often share with humanists the attempt to improve values in their communities.

As well as affirming the dignity or value of human beings, religions also have something to say about other forms of life on the planet (see also 9.c). Food laws including vegetarian and vegan orientations and carefully prescribed systems of animal slaughter for meat have a respected place in many religious traditions.

\section{Questions of Right and Wrong}

The law of the land in most countries is a secular legal system enforced by police, judges and a penal system. Because religions are ways of life as well as belief-systems, they too have ideas about how people should behave and what should be done when they behave badly. They also have their own teachings about justice and a way for people to show that they are sorry for what they have done. But one of the main characteristics of religion is its sense that order, truth and justice are ultimate cosmic values and realities, not just human ideas. They are part of the way God wants things to be, to put it in theistic terms, not just the creations of human societies. They are the very nature of Enlightenment and Wisdom, to use other terminology.

There is obviously a great deal of overlap between what religions and the law of the land discourage - for example, theft and murder. The ideas of a religion about what are good and bad, right and wrong ways of behaving have 
often affected a society in which that religion has been a majority presence for a long time - for example, Christianity and the law of monogamy in Europe. Religious people are in any case almost always encouraged to obey the law of the land in which they live, except where they believe that the law is unjust or inhumane. Then they may feel that they have to make a protest, preferably, though not always, in a non-violent way, against injustice and seek to change things through the appropriate channels of that society.

In these ways religions tend to think of two levels of law. There is the ultimate law, which some see as karma and others as the Will of God, and which, for example, may condemn all killing and see it as bringing serious punitive consequences. Then there is the lower law of a nation or state which asks soldiers to go to war to protect their country (see 8.b), or which inflicts capital punishment for serious crimes such as murder. Whilst murder is wrong, not all killing is murder and most traditions would argue that there may sometimes have to be actions which are justified as a lesser evil because of the circumstances. Another example is that religions see punishment as a matter for God, who is both just and merciful; or as part of the law of karma, which is based on the intention, the attitude and heart of a person, not just on their external actions. Repentance and forgiveness are then always a possibility between people and God, or between human beings. In human society, however, the state inflicts punishments for crimes, based mainly on external actions and with some reference to motive and intention, but independently of the issues of forgiveness and reconciliation. Crimes about which the state legislates are termed illegal. The religions have their own technical terms for what is considered wrong in their traditions. The Christian term is 'sin' but one should beware of using that term to translate the related concepts of other religions. We have indicated this by giving section B.6.b. a different title. Other related terms are the idea of what is and is not meritorious, making good or bad merit. Teaching about what is right and wrong is also related to beliefs about life after death and how a person's present life affects their future state.

\section{Equality and Difference}

People often point out that religions cause conflict and divide people (see section 8). In any consideration of the ethics of religious communities this challenge must be met. If religions create hatred and evil then their claim to present moral or ethical standards is almost totally undermined. It is necessary to examine what they have to say about differences between people. It would be facile to pretend that there are no differences, and quite clearly the different religions are in themselves responding to different kinds of cultural perceptions, experiences and attitudes.

While some find it relatively easy to accommodate the fact that people are infinitely varied, it is sometimes harder to find a way of coping with other 
religions as such, which often claim not only to know a different truth but sometimes exclusively to know the truth. It is interesting to note that there can be more problems in attitudes towards those religions closely related, who are considered in some way to be heretics or seceders, than towards those religions at a distance. Religions vary in their attitudes to diversity of views. It is perhaps more common to conflict with members of one's family than with people who are strangers.

Related to this, but on a more political or social level, is the attitude of one community towards people of other races or nations. Some religions see themselves as very definitely relevant to all races or nations, while others are rather more restricted to a particular community or group. This has not prevented the large communities from breaking down into sub-groups related to race or nation, nor has it prevented the rather more restricted groups from opening up to embrace others not of their original community. Unless religions can provide an adequate and dignified response to these groupings, which sometimes conflict, they will be criticised as not able to teach much in the way of ethics.

Perhaps an even more fundamental split in humanity is that between the sexes; religions, like all cultural groups, have been challenged by the modern movements for women's equal rights, often called feminism. These seek to show how patriarchal religions as well as other social groupings are. The questions that are asked involve the nature of the relationship between the sexes and gender-determined roles. Are the sexes of differing status, of differing purpose, or merely different? Many religions have been influenced by the cultural environment in which they have operated, but equally many cultural environments have been influenced by the religions which operate within them. It is very hard to trace whether the contemporary experience of women is a product of local religious ideas, or whether the religious communities can offer something in the context of modern feminism.

Overarching all these issues is the question of whether or not all people are equal and if so, what is the purpose of different religions and how does one deal with the various ways in which humanity tends to divide itself? Once again, and by easy reference to common knowledge, one can see that religious teachings have often been used to aggravate the sense of the inequalities between people, and to support the claims of one group against another and used power based on ethnicity, colour or gender inappropriately. Is the religion being correctly interpreted in such a case, or is it being misused?

Another important issue, as touched on previously, is the relationship between the secular civil and human rights movements and traditional religions and whether, as some humanists might argue, the secular movements present the challenge of a more advanced international ethic. This section, with its various topics, points most specifically at the heart of the potential humaneness of religions, and their claim to moral and ethical insights worthy of being considered even by people of other religions or no religion at all. 


\section{Conflict and Violence}

All the religious traditions have different ways of looking at the origins of and reasons for conflict but these all relate in some way to the absence of the personal qualities laid out in 2.a. and the issues of sinfulness, disobedience and wrong actions explored in section 6 .

Sections $b$ and $c$ within this topic imply that the existence of different ethnic groups and separate nations is in some way a problem. Our experience of nations is as competitors and enemies rather than as collaborators and friends (7.c). The competition may be for trade, land, resources, olympic medals or ideological superiority.

People tend to mean by a nation a humanly created nation-state rather than an ethnic grouping with an inherited common culture (7.a). Such a nation often has quite artificial, arbitrary geographical boundaries and separates related groups of people such as Sikhs in the Punjab or ethnic Germans in central Europe and the Kurds in Turkey and Iraq. Many are relatively modern. So the answer to the question of why different nations exist is most commonly given in historical, social, geographical and nationalistic, rather than religious, terms, though there are some examples linked with religion as with the partition of Pakistan in 1947 (see F.8.b) and the creation of the state of Israel in 1948 (see D.8.b).

The majority of the nation-states of today contain a diversity of cultures and religious groupings within them. They are plural, multi-cultural and multi-religious. It is possible for a nation to affirm this variety as a microcosm of the varied world in which we live. Members of religions might then feel secure living side by side. However, there is sometimes a tension between religious beliefs and practices and commitment to separate nation-states. The state may be oppressive of the religion of some religious groups or be intolerant of customs which to religious people are essential to the practice of their religion. Examples of the latter are the wearing of the hijab by Muslim women and girls or the carrying of the Sikh kirpān, which might count as an offensive weapon, or the obligation on a Jewish person not to work during the twenty-five hours of the Sabbath, which is from sunset on Friday to nightfall on Saturday. There may be a desire to create and live in a nation in which one can follow one's religious life and its ethical ideals with the minimum of compromise. This desire may lead to a radical reform of a nation from within (as in the case of the Iranian Revolution) or the setting-up of a new nationstate - as in the case of Pakistan in 1947 and the Sikh desire for a homeland, which would be called Khalistan (see C.8.b). Religious beliefs may emphasise that fellowship with co-religionists in other nation-states transcends national divisions and loyalties (see F.8.b). There may be a deep awareness of the final unity of all humankind whatever their religion or race (see $7 . \mathrm{b}$ and c), and a desire for the global village to see itself and act as one world. All of these views are reflected in this section. 
Some of the above points are highlighted when nations go to war against each other. Many religions teach some form of non-violence as an ideal, and members of religions have often refused to fight (see 8 . a, c and d). They maintain that their refusal to be involved in the killing of others is more important than blind loyalty to a nation-state or even more than its defence, if it is threatened by others. This has never been an easy option since people who take this stand might be imprisoned or expected to undertake dangerous tasks in war zones, such as working with ambulance crews. Some religions teach that war might be acceptable and even obligatory in certain circumstances such as self-defence or to end tyranny or oppression (see 8.d). If war becomes necessary, then careful conditions are traditionally laid down about how it should be waged, with as much respect given to civilian life and property and the humane treatment of prisoners, for example, as possible. Nuclear, chemical and biological warfare is of quite a different kind from traditional warfare. It is not just a matter of degree and the number of people that would be involved in the present and the future, but also of its indiscriminate nature (see 8.e). These are just some of the contemporary challenges that those with religious perspectives are needing to consider.

Many of the issues involved in discussion of war and peace overlap those involved in violence and non-violence amongst individuals. It is often more difficult for members of religious traditions who have high ideals for family life and communities (see 3.b) to acknowledge the existence of violence and conflict within the home and that members of their communities are involved in other forms of social violence. The ethics of some religions stress that families, societies and nations are no more than a collection of individuals, and that the best way to secure peaceful co-existence is to tackle aggression, hatred, greed, jealousy and so forth, on an individual level.

\section{Global Issues}

The modern awareness of the world as a 'global village' has brought to everyone's attention the problems of people around the world. Only a century ago it was possible to be fairly ignorant as to what was happening just a few hundred miles away, but nowadays it is almost impossible to ignore what is happening on the other side of the world, particularly when the happening is a crisis of some sort.

There is much evidence to suggest that what is called the 'north-south divide' in the world demonstrates an injustice of monstrous proportions. Most of the countries in the northern hemisphere are relatively affluent and frequently waste a large amount of the food and resources that they have available, simply because they cannot consume them all. Meanwhile many of the countries in the southern hemisphere are starved and impoverished. Thousands of people die of famine, disease and natural disasters against which they cannot afford to establish proper defences. The problem of world 
poverty seems to be one which is to do with justice rather than resources, and challenges to solve it belong equally to all people.

Some people have blamed the poverty in the less technologically developed countries on the tendency of their populations to grow faster than those in the more affluent countries of the northern hemisphere. This is by no means a total explanation and in some ways a complete red herring. Nevertheless, each community is challenged by the situation to develop an attitude towards the growth of the world's population and the fact that humanity possesses the capacity to control or reduce its numbers, if it so wishes. Should people, as it were, 'trust in God' and carry on producing children? Should people engineer a certain population size, in line with economic realities? A third possibility is, of course, to try to adjust economic realities to suit the size of population. As with other issues, the questions overlap those asked and the answers given where reproduction is considered in section 5.c.

Whatever the approach, the size of population in some impoverished countries has been seen as a major problem, and it is worth considering that the other side of the problem is the diminishing size of the populations of affluent countries. In time there is a fear that either there will be an insufficient workforce, or there will not be enough people to support the elderly, who through medical advances are living longer. Here again there is overlap with the discussions in sections 5.a. and b.

All this awareness and concern about global problems encourages a view of the world as a completely interrelated whole as one world. Perhaps it was space travel and the images of planet earth from the moon, spaceships and satellites that most dramatically established for all people that the world is a single unit spinning in space, and that everything that happens in this one place will eventually have an impact on everywhere else. The development of concern for the environment, for ecological systems, for the conservation of fish stocks, for fossil fuels, and the attempt to prevent the atmosphere from deteriorating still further are all demonstrations of a growing awareness that regardless of differences, every community finally bears a relationship with and responsibility to every other community. And the family of related beings is not only a family of human beings, but of humans in their interdependence and relatedness to all other forms of life.

Even though this may not have been a major preoccupation in the days of the establishment of the main religious traditions, if they are to be relevant to the modern day they must say something about how human beings should respond to the concept of the world as a whole and its natural needs, in the light of the growing human capacity to affect the way the world progresses. As they look back as well as forward in their scriptures, traditions and interpretations of these, many people of faith feel confident that their voices are not only relevant, but also forward-looking in this regard. 